Skinner, F. A., Jones, P. C. T. \& Mollison, J. E. (1952). J. gen. Microbiol. 6, 261-271.

\title{
A Comparison of a Direct- and a Plate-counting Technique for the Quantitative Estimation of Soil Micro-organisms
}

\author{
By F. A. SKINNER, P. C. T. JONES AND J. E. MOLLISON \\ Soil Microbiology Department, Rothamsted Experimental Station, Harpenden, \\ Hertfordshire
}

SUMMARY : Estimates of numbers of micro-organisms occurring in three differently manured soils, made by a direct-counting and plating technique, were compared. No correlation was found between the two methods and reasons for the large discrepancy between them are discussed. Contradictory information of the effect of external factors on soil micro-organisms can be given by the two different methods of counting.

Estimates of the total numbers of bacteria in soil obtained by a direct-counting technique devised by Jones \& Mollison (1948) are of the order of several thousands of millions/g. soil, while estimates by conventional plating methods are in tens of millions/g., even on the least selective media so far used. The same authors found a difference of the same kind between the quantity of fungal mycelium in soil as estimated by a direct count of number of pieces/g. as compared with colony plate counts, although in this comparison the former count is only $2-6$ times greater than the latter.

The effect of external factors such as soil moisture and temperature on the various groups of soil microflora has been investigated by several workers and, while certain correlations have been found, the results have been conflicting. The estimations of numbers of organisms were mainly based on plate counts. The present investigation was undertaken to compare direct counts with plate counts over a period of time, to determine how these varied with soil moisture and temperature and to show whether these two counting methods did, in their different ways, give the same sort of information about the soil population. The soils of three differently manured plots were sampled at intervals (Fig. 1) over the greater part of a year, and determinations made of the moisture content of these samples and of their bacterial, fungal and actinomycetal populations, by plating and a direct-counting technique.

\section{METHODS}

Soil sampling. The soil samples were taken from three of the classical plots of Broadbalk field, which has grown wheat continuously for just over 100 years and whose plots have had different manurial treatments over that period. Plot 2 (farmyard manure), plot 3 (no manure) and plot 7 (complete minerals + ammonium sulphate) were sampled at intervals between January and December. Soil was collected by an auger to a depth of 4 in. in 12 areas on each plot; these were bulked and passed through a $3 \mathrm{~mm}$. sieve. From these sieved samples the necessary amounts of soil were taken for the determination 
of moisture content, for the dilutions required for plating for the estimations of bacteria, fungi and actinomycetes and for preparing films for direct counting. The same samples of soil were used for estimating the numbers of amoebae present; these results were published separately (Singh, 1949).

Media. For plating bacteria and actinomycetes a non-selective medium, based on the 'artificial soil solution' used by Erikson (1947) was prepared; it had the following composition: $\mathrm{Ca}\left(\mathrm{NO}_{3}\right)_{2}, 0.33 \mathrm{~g}$.; $\mathrm{CaSO}_{4}, 0.8 \mathrm{~g}$.; $\mathrm{MgSO}_{4} 7 \mathrm{H}_{2} \mathrm{O}$, 0.7 g.; $\mathrm{K}_{2} \mathrm{SO}_{4}, 0.025$ g.; $\mathrm{K}_{2} \mathrm{HPO}_{4}, 0.005$ g.; $\mathrm{NaHCO}_{3}, 0.2$ g.; distilled water to $1 \mathrm{l}$. To $1 \mathrm{l}$. of this solution were added: glucose, $0.01 \mathrm{~g}$.; Difco yeast extract, 0.005 g.; $\mathrm{FeCl}_{3}$, trace; water-washed agar, $15 \mathrm{~g}$. The $\mathrm{pH}$ was $\mathbf{7 \cdot 2}$.

From the sieved soil $10 \mathrm{~g}$. were taken to make the primary suspension from which further dilutions were made in $0.75 \%(\mathrm{w} / \mathrm{v}) \mathrm{NaCl}$. Five replicate plates were made at a final dilution of $1 / 250,000$ using $15 \mathrm{ml}$. portions of the above medium per plate. The plates were incubated at $25^{\circ}$ for $\mathbf{2}$ weeks. Although the growth of all organisms was slow on this medium, high counts had been obtained in preliminary tests. A total count of both bacterial and actinomycete colonies was then made with a hand-lens. An actinomycete colony count was made after a microscopic examination of the plates, when finely filamentous colonies, mainly streptomyces and micromonospora, were marked. Filamentous colonies of pasty consistency (Nocardia spp.) were not counted.

For plating fungi, Czapek-Dox and Waksman's fungus-agar (Waksman, 1927 , p. 19) were used; these media were adjusted to $\mathrm{pH} 4 \cdot 6$. Later Conn's glycerol sodium asparaginate medium was also used (Fred \& Waksman, 1928); it has a lower nutrient value and under test proved to be less selective and to give higher total counts than many other general media for fungi (Brierley, Jewson \& Brierley, 1927). Of the sieved soil $25 \mathrm{~g}$. were used to make a primary dilution of 1/10, which was hand-shaken for $20 \mathrm{~min}$. A final dilution of $1 / 20,000$ was used for eight replicate plates having $10 \mathrm{ml}$. medium/plate. Final counts were made after incubation for 9 days at $25^{\circ}$.

Direct-counting technique. Direct counts of numbers of bacteria and of the number of pieces and total length of mycelium were estimated exactly as described by Jones \& Mollison (1948) with one modification. In the original paper the counting of fungal mycelium with a low-power $\left(\frac{2}{3}\right)$ objective was advocated. In the present investigation counts were made under a $\frac{1}{6}$ objective over the whole field. Although with the lower power a larger number of observations per field is made, giving possibly greater accuracy in the final estimation, there is some difficulty in identifying the smaller fungal fragments and of measuring them. Higher counts are obtained using the $\frac{1}{6}$ objective, as many fine filaments not resolved under a $\frac{2}{3}$ objective are readily seen with the higher power.

Soil suspensions used for the direct and plate counts were made from two portions of the same soil sample but were prepared in different ways. For the direct count the initial suspension was made by grinding a weighed quantity of soil with $15 \mathrm{ml}$. distilled water, while for the plate count the initial suspension was shaken only. This fundamental difference in technique might be considered a source of discrepancy in the estimate of numbers of organisms, but a smal 1 
experiment to compare two plate counts, one made by the usual shaken suspension and the other by grinding the soil in the initial suspension before dilution, showed this not to be so. Two soils, a poor soil represented by Broadbalk plot 3, and a rich allotment sample, were used. From each sample $10 \mathrm{~g}$. were used to make a primary suspension, which was shaken, and a final dilution of 1/250,000 was used for plating. A further $2.58 \mathrm{~g}$. from each soil sample was ground up by a glass rod in $15 \mathrm{ml}$. distilled water, as in the preliminary stages of making soil films (Jones \& Mollison, 1948). One ml. was removed to make a final dilution of $1 / 250,000$ for plating, while the remaining $14 \mathrm{ml}$. were used for the direct-count films. The results of this experiment are shown in Table 1, which shows that though the ground suspension gave the higher plate count in both cases, the difference between the two plate counts was not appreciable and the discrepancy between the plate and total direct count was still 40-50-fold. The difference between the direct colony count and the plate count is approximately 20 -fold.

Table 1. Comparison of direct count with plate count of bacteria using two methods for preparing soil suspensions for the plate count

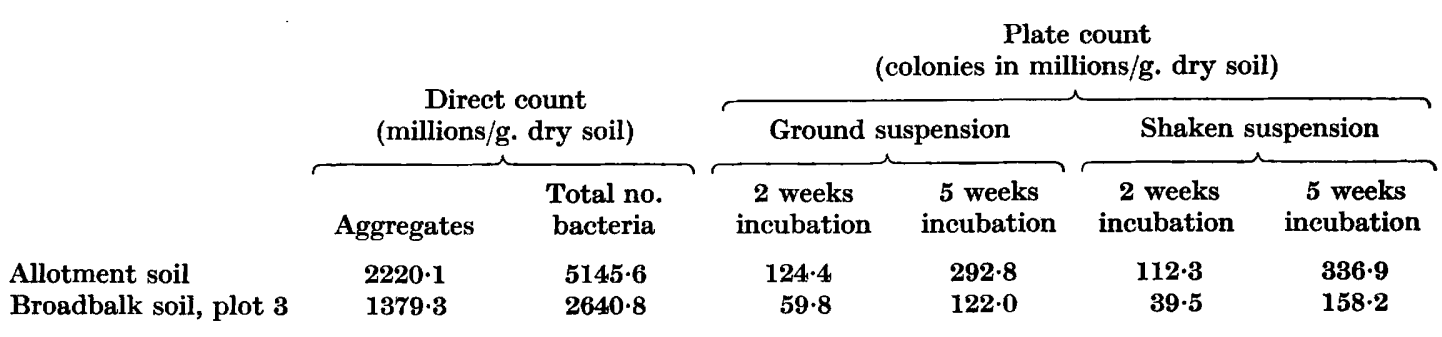

The plates from the last experiment were kept, and since they had not dried out were recounted after an incubation period of 5 weeks. Table 1 shows that after 5 weeks the number of colonies had increased to two or three times the number found after the more usual incubation period and that the shaken suspension now gave the higher figures. The discrepancy between the direct and plate counts was here reduced approximately to one of 10-20-fold.

Moisture content. Samples ( 25 g.) were taken from the sieved soil samples and dried overnight at $105^{\circ}$.

Soil temperature. The temperatures for a depth of 4 in. of soil were taken from those of the Rothamsted meteorological records, which are made on an area about half a mile distant from Broadbalk.

Statistical analysis. Correlation coefficients were used to assess the agreement between the numbers of organisms/g. soil estimated by the two methods and to show whether or not these numbers were dependent on changes in soil moisture and temperature. The correlations and regressions for the three plots were found not to differ significantly amongst themselves and were therefore pooled. 


\section{RESULTS}

The estimated total numbers of bacteria, fungi and actinomycetes are shown against the sampling dates in Figs. 1 and 2. The numbers of bacteria obtained from plate counts were, with one exception, consistently higher on plot 2 than on plots 3 and 7, which were very similar. By the direct counting method the total numbers of bacteria were $40-50$ times higher than by the plating method. Plot 2 again showed consistently higher numbers than plots 3 and 7 which were again similar. It is seen from Table 2 that there is no correlation between the two methods for bacterial counts. A partial correlation calculated after eliminating the effect of soil moisture and temperature was still not significant. This reflects the findings of Taylor (1936), who made a similar comparison between plate counts and a total count obtained by the ratio method of Thornton \& Gray (1934).

Table 2. Correlation coefficients between plate and direct counts of bacteria, fungi and actinomycetes

\begin{tabular}{|c|c|c|c|c|c|c|c|}
\hline \multirow[b]{3}{*}{ Correlation coefficients between: } & \multicolumn{3}{|c|}{ Broadbalk } & \multirow{3}{*}{\multicolumn{2}{|c|}{$\begin{array}{c}3 \text { plots } \\
N \text { aggregated }\end{array}$}} & \multirow[b]{2}{*}{ D.F. } & \multirow[b]{2}{*}{$\boldsymbol{P}$} \\
\hline & Plot 2 & Plot 3 & Plot 7 & & & & \\
\hline & & & & & & & \\
\hline Direct bacteria and plate bacteria & -0.347 & 0.032 & -0.488 & 7 & -0.286 & 17 & - \\
\hline $\begin{array}{l}\text { Partial correlation-moisture and tempera- } \\
\text { ture eliminated }\end{array}$ & 一 & - & - & - & $-0 \cdot 331$ & 15 & - \\
\hline Direct bacteria and plate actinomycetes & 0.392 & $0 \cdot 342$ & 0.622 & 7 & $0 \cdot 438$ & 17 & $0.05-0 \cdot 1$ \\
\hline $\begin{array}{l}\text { Partial correlation-moisture and tempera- } \\
\text { ture eliminated }\end{array}$ & - & - & - & - & $0 \cdot 189$ & 15 & - \\
\hline Plate bacteria and plate actinomycetes & -0.553 & 0.597 & -0.320 & 7 & -0.511 & 17 & $0.02-0.05$ \\
\hline $\begin{array}{l}\text { Partial correlation-moisture and tempera- } \\
\text { ture eliminated }\end{array}$ & & - & - & - & -0.277 & 15 & - \\
\hline $\begin{array}{l}\text { Direct fungi and plate fungi (Waksman's } \\
\text { medium) }\end{array}$ & 0.725 & $0 \cdot 141$ & 0.015 & $\mathbf{9}$ & $\mathbf{0 . 3 2 4}$ & 23 & - \\
\hline $\begin{array}{l}\text { Partial correlation-moisture and tempera- } \\
\text { ture eliminated }\end{array}$ & - & - & - & - & 0.089 & 21 & - \\
\hline Direct fungi and plate fungi (Czapek's medium) & 0.428 & 0.622 & 0.354 & 8 & 0.412 & 19 & $0 \cdot 05-0 \cdot 1$ \\
\hline Direct fungi and plate fungi (Conn's medium) & - & - & - & 6 & $0 \cdot 409$ & 14 & - \\
\hline $\begin{array}{l}\text { Direct fungi (no. of pieces) and direct fungi } \\
\text { (total length) }\end{array}$ & $0 \cdot 805$ & 0.731 & 0.815 & 11 & - & - & 0.01 \\
\hline
\end{tabular}

$N=$ number of pairs of observations ; D.F.= degrees of freedom; $P=$ level of significance.

Significant correlation coefficients in black type.

The highest counts of actinomycetes by the plate method were obtained from the plot treated with farmyard manure while the other two were very similar, with the unmanured plot showing a tendency towards higher numbers (Fig. 1). These figures confirm earlier work by J. Singh (1937), who found that Broadbalk plot 2 carried a much heavier actinomycete flora than plot 3. His figures were much lower than the present ones, probably due in part to his having used a medium of $\mathrm{pH} 5 \cdot 4$, which is just above the lower limit for actinomycete development, and because in the present investigation one of us (F.A.S.) used microscopic observation for the final identification of each actinomycete colony. 
To determine whether bacterial and actinomycete populations fluctuate in a parallel manner, the correlation coefficient was calculated between their respective plate counts and between the bacterial direct count and actinomycete plate count. Direct counts of actinomycetes are not possible at present owing to the difficulty of distinguishing their filaments from fungal hyphae and their spores from bacteria. The aggregated correlation coefficient shows

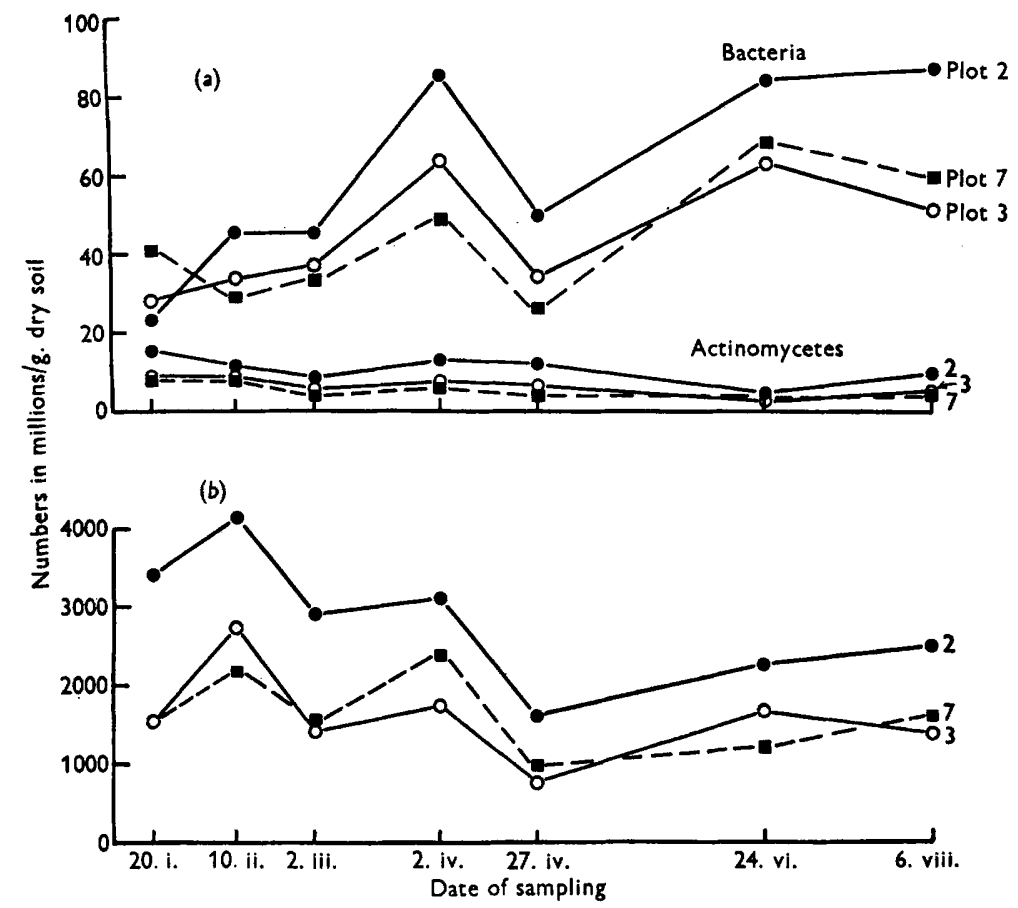

Fig. 1. (a) Plate counts of soil bacteria and actinomycetes in the three plots of Broadbalk field on different dates in 1948. (Plot 2, farmyard manure; plot 3, unmanured; plot 7, complete mineral fertilizer.) (b) Direct counts of soil bacteria in the same plots as in $(a)$.

the plate counts to be negatively and significantly correlated, whereas the correlation between the direct bacterial count and the plate actinomycete count is of marginal significance $(P=0 \cdot 1)$. However, when the effects of soil moisture and temperature were eliminated, the partial correlations between both pairs of counts showed no correlation (Table 2).

The numbers of viable fungal particles estimated in thousands/g. obtained by plate counts of colonies on Waksman's medium are shown in Fig. 2. The numbers found in plot 3 were consistently the lowest; plot 7 gave the highest figure on seven of nine occasions. On Czapek's medium the numbers obtained were of the same order; again plot 3 showed consistently the lowest figures and plot 7 the highest on seven of eight occasions. On six of the sampling dates (May-December) fungal counts were also made on Conn's medium. The total numbers fluctuated in a similar manner for all plots but were higher than those 
obtained on the other three media: plot $2,280 \times 10^{3}$ to $430 \times 10^{3}$ colonies/g.; plot $3,130 \times 10^{3}$ to $275 \times 10^{3} / \mathrm{g}$; ; plot $7,210 \times 10^{3}$ to $515 \times 10^{3} / \mathrm{g}$. Plot 3 gave consistently the lowest count, but plot 7 was not so consistently higher than plot 2.

Direct counts of number of pieces of mycelium/g. of soil are shown in Fig. 2. These estimates are from 2 to 6 times those of the plate counts. Although plot 3 had a tendency to show the lowest figures, this method has shown less consistent differences between the numbers on the three plots. The pieces of mycelium observed and counted were also measured by a micrometer eyepiece and the total length of mycelium was calculated and expressed as m./g. soil. Plot 2 showed 33-65 m., plot 3, 25-57 m., and plot 7, 25-63 m./g. soil.

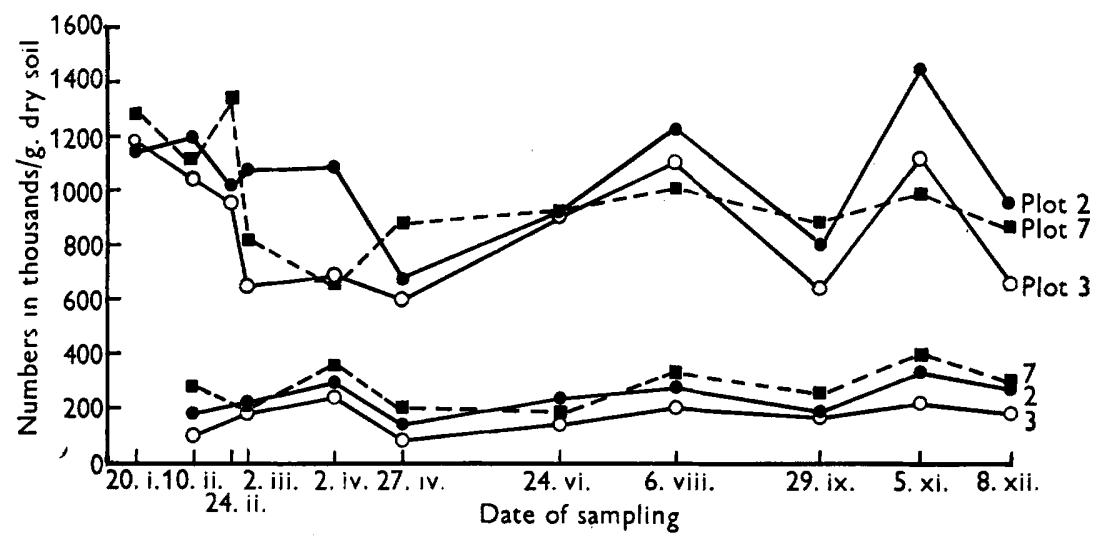

Fig. 2. Upper curves : direct counts of soil fungi expressed as number of pieces of mycelium/g. dry soil. Lower curves : plate counts of soil fungi on Waksman's medium expressed as number of colonies on plate/g. dry soil.

The agreement between the plate and direct methods using the figures for number of pieces of mycelium is not good, as indicated by the correlation coefficients (Table 2); these are positive but only barely significant for plot 2 on Waksman's medium and for plot 3 on Czapek's medium. When the calculation is made on the aggregated observations for three plots, the correlation between the methods is just below the level of significance for all three media. When the effects of soil moisture and temperature are eliminated any relationship between the two counts disappears.

The two estimates of mycelial quantity, number of pieces of mycelium and total length, parallel each other very closely, and a highly significant agreement appears between them for every plot (Table 2). However, the counting of pieces-an easier task than their measurement-does not necessarily give the true picture of the development of mycelium in soil. The average length of pieces measured in one investigation could be much higher than in another, so that while correlation with number of pieces might be good in both, the ratio of number of pieces : total length could be different. This did not reveal itself in the present work, but inconsistency in the grinding of soil for making 
soil films and differences in fragmentation of hyphal filaments could make this a possibility.

The figures for percentage moisture content and temperature of the soil for the dates of sampling are given in Table 3. In investigating the effect of soil moisture and temperature on the numbers of bacteria and of fungi, it was

\section{Table 3. Soil moisture and temperature}

\begin{tabular}{|c|c|c|c|c|}
\hline \multirow[b]{2}{*}{ Date } & \multicolumn{3}{|c|}{ Moisture content ( $\%)$} & \multirow[b]{2}{*}{ Soil temperature } \\
\hline & Plot 2 & Plot 3 & Plot 7 & \\
\hline 20. i. 48 & $23 \cdot 45$ & $18 \cdot 99$ & $20 \cdot 59$ & $0.7^{\circ}$ \\
\hline 10. ii. 48 & $19 \cdot 88$ & $15 \cdot 72$ & $17 \cdot 08$ & $5 \cdot 5^{\circ}$ \\
\hline 24. ii. 48 & $20 \cdot 70$ & $16 \cdot 90$ & $17 \cdot 50$ & $0 \cdot 6^{\circ}$ \\
\hline 2. iii. 48 & $18 \cdot 44$ & $13 \cdot 16$ & $14 \cdot 24$ & $\mathbf{3 \cdot 3 ^ { \circ }}$ \\
\hline 2. iv. 48 & $20 \cdot 50$ & $15 \cdot 12$ & $16 \cdot 92$ & $5 \cdot 1^{\circ}$ \\
\hline 27. iv. 48 & $9 \cdot 76$ & $8 \cdot 36$ & $8 \cdot 68$ & $11 \cdot 3^{\circ}$ \\
\hline 23. vi. 48 & $17 \cdot 36$ & $14 \cdot 40$ & $15 \cdot 48$ & $13 \cdot 5^{\circ}$ \\
\hline 6. viii. 48 & $15 \cdot 60$ & $12 \cdot 20$ & $13 \cdot 40$ & $17 \cdot 7^{\circ}$ \\
\hline 29. ix. 48 & $16 \cdot 28$ & $11 \cdot 96$ & $12 \cdot 60$ & $13 \cdot 5^{\circ}$ \\
\hline 5. xi. 48 & $21 \cdot 00$ & $16 \cdot 00$ & $16 \cdot 80$ & $6 \cdot 8^{\circ}$ \\
\hline 8. xii. 48 & $22 \cdot 30$ & $16 \cdot 80$ & $19 \cdot 00$ & $7 \cdot 8^{\circ}$ \\
\hline
\end{tabular}

Table 4. Correlation coefficients between plate and direct counts of bacteria and soil moisture content and temperature

\begin{tabular}{|c|c|c|c|c|c|c|}
\hline & \multicolumn{3}{|c|}{ Broadbalk } & \multirow{2}{*}{\multicolumn{2}{|c|}{$\begin{array}{c}3 \text { plots } \\
\text { aggregated }\end{array}$}} & \multirow[b]{2}{*}{ D.F. } \\
\hline & Plot 2 & Plot 3 & Plot 7 & & & \\
\hline \\
\hline Direct bacteria and moisture content & $0 \cdot 618$ & $0 \cdot 480$ & $0 \cdot 4,4$ & 10 & 0.533 & 26 \\
\hline & & & & - & $0 \cdot 327$ & 25 \\
\hline Plate bacteria and moisture content & -0.309 & -0.065 & $0 \cdot 185$ & & $-0 \cdot 118$ & 17 \\
\hline lation-temperature eliminated & & & & - & & 16 \\
\hline 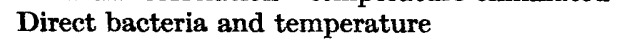 & -0.655 & -0.347 & $-0 \cdot 448$ & 10 & $-0 \cdot 496$ & \\
\hline lation-moisture eliminated & & & & - & $-0 \cdot 245$ & \\
\hline and temperature & 0.712 & $0 \cdot 480$ & 0.569 & & 0.591 & \\
\hline Partial correlation-moisture eliminated & - & - & - & - & & 16 \\
\hline \multicolumn{7}{|c|}{$\begin{array}{c}N=\text { number of pairs of observations; D.F. }=\text { degrees of freedom; } P=\text { level of significance. } \\
\text { Significant correlation coefficients in black type. }\end{array}$} \\
\hline \multicolumn{7}{|c|}{$\begin{array}{l}\text { found that direct and plate counts often indicated conflicting relations. For } \\
\text { instance, a positive significant correlation was found between soil temperature } \\
\text { and bacterial plate counts, whereas a negative significant one obtained between } \\
\text { soil temperature and bacterial direct counts. If the interaction of moisture be } \\
\text { taken into account, no correlation is then found between bacterial direct } \\
\text { count and temperature (Table 4). The effect of moisture on bacterial numbers } \\
\text { assessed by plate counting is not significant but tends to be an inverse rela- } \\
\text { tion, while by direct counting it is a positive and highly significant effect, } \\
\text { when judged by a total correlation. With the elimination of the effect of } \\
\text { temperature, both methods of counting show a positive and barely significant } \\
\text { relation with moisture. Further data on the effect of moisture and temperature } \\
\text { on fungi and actinomycetes are given in Table } 5 \text {. Actinomycetes show a small, } \\
\text { positive total correlation with moisture, significant in plot7, and a high negative }\end{array}$} \\
\hline
\end{tabular}


correlation with temperature, significant in plot 7 and for the three plots together. The direct fungal count also shows a significant correlation with moisture but not for temperature. The plate counts of fungi on Czapek and on Waksman media give total correlations with moisture and temperature which are not very similar, although the figures for the individual plots for each medium are fairly consistent, with the notable exception of plot 7 on Czapek medium. A much greater number of observations would have to be made before any explanation of these results could be offered.

Table 5. Correlation coefficients between fungi and actinomycetes and soil moisture content and temperature

\begin{tabular}{|c|c|c|c|c|c|c|c|}
\hline \multirow[b]{3}{*}{ Correlation coefficients between: } & \multicolumn{3}{|c|}{ Broadbalk } & \multirow{3}{*}{$N$} & \multirow{3}{*}{$\begin{array}{c}3 \text { plots } \\
\text { aggregated }\end{array}$} & \multirow{3}{*}{ D.F. } & \multirow{3}{*}{$\boldsymbol{P}$} \\
\hline & Plot 2 & Plot 3 & Plot 7 & & & & \\
\hline & & & & & & & \\
\hline Plate actinomycetes and moisture content & 0.278 & 0.429 & 0.800 & 7 & 0.448 & 17 & $0.05-0.1$ \\
\hline Plate actinomycetes and temperature & -0.586 & 0.687 & $-0 \cdot 712$ & 7 & -0.633 & 17 & $0 \cdot 01$ \\
\hline Direct fungi and moisture & 0.590 & 0.544 & 0.418 & 11 & $\mathbf{0 . 5 1 7}$ & 29 & 0.01 \\
\hline Direct fungi and temperature & $-0 \cdot 268$ & -0.139 & $-0 \cdot 404$ & 11 & -0.266 & 29 & - \\
\hline Plate fungi (Waksman's medium) and moisture & 0.678 & $0 \cdot 424$ & 0.518 & $\mathbf{9}$ & $\mathbf{0 . 5 5 0}$ & 23 & 0.01 \\
\hline Plate fungi (Czapek's medium) and moisture & $0 \cdot 273$ & $0 \cdot 695$ & $-0 \cdot 005$ & 8 & $0 \cdot 142$ & 19 & - \\
\hline $\begin{array}{l}\text { Plate fungi (Waksman's medium) and tempera- } \\
\text { ture }\end{array}$ & $-0 \cdot 127$ & $-0 \cdot 125$ & $-0 \cdot 161$ & 9 & - & - & 一 \\
\hline Plate fungi (Czapek's medium) and temperature & $0 \cdot 356$ & $0 \cdot 561$ & 0.587 & 8 & 0.453 & 19 & $0.02-0.05$ \\
\hline
\end{tabular}

$N=$ number of pairs of observations; D.F. $=$ degrees of freedom; $P=$ level of significance. Significant correlation coefficients in black type.

\section{DISCUSSION}

In the present investigation direct counts of numbers of bacteria and fungi were always much higher than those of corresponding plate counts, and the two methods gave different information about their fluctuations. Several factors may contribute to the large discrepancy in numbers given by the two methods: (1) clumps of bacteria which remain aggregated in spite of the shaking that precedes plating; (2) staining of non-viable particles in direct count preparations; (3) failure to distinguish between bacteria and actinomycete spores, and between fungal and actinomycete filaments in stained films; (4) competition on plates; (5) selectivity of plating media and non-cultivation of obligate anaerobes.

The frequency with which plate colonies develop from aggregates of bacteria rather than from individual cells is not easy to assess but there is strong evidence that this must occur. It is shown in Table 6 that the number of observations of cells in 'colonies' of two or more was about the same as that of single cells. These small aggregates had resisted grinding in the preparation of the soil films, and it is unlikely that similar ones would have disintegrated into their component cells during the shaking that preceded plating. If, as is probable, aggregates such as those observed in soil films gave rise to only single colonies on plates, this alone would have made the direct count approximately double the plate count. Further, a minute soil particle bearing several 
individuals or even aggregates of different species might give only one colony on a plate. The occurrence of impure colonies on plates suggests strongly that this may frequently happen.

Table 6. Analysis of bacterial aggregates occurring on soil films

\begin{tabular}{|c|c|c|c|c|c|c|c|c|}
\hline \multirow[b]{3}{*}{ Slide no.: } & \multicolumn{8}{|c|}{ No. aggregates per slide } \\
\hline & \multicolumn{4}{|c|}{ Broadbalk (plot 3) } & \multicolumn{4}{|c|}{ Allotment } \\
\hline & $\mathbf{1}$ & $\mathbf{2}$ & $\mathbf{3}$ & 4 & 1 & 2 & $\mathbf{3}$ & 4 \\
\hline \multicolumn{9}{|l|}{$\begin{array}{l}\text { No. of cells } \\
\text { in aggregate }\end{array}$} \\
\hline 1 & 62 & 49 & 61 & 63 & 85 & 82 & 82 & 89 \\
\hline $\mathbf{2}$ & 35 & 30 & 31 & 16 & 31 & 32 & 34 & 48 \\
\hline 3 & 4 & 6 & $\mathbf{3}$ & 6 & 7 & 6 & 8 & $\mathbf{5}$ \\
\hline 4 & 9 & 12 & 2 & $\mathbf{3}$ & 9 & 15 & 11 & 15 \\
\hline 5 & 4 & 2 & 3 & 2 & 2 & 7 & 9 & 3 \\
\hline 6 & 2 & 3 & 1 & 2 & 6 & 4 & $\mathbf{5}$ & 5 \\
\hline 7 & $\overline{1}$ & - & - & 2 & - & - & 1 & 1 \\
\hline 8 & - & 2 & 2 & - & 1 & 1 & 1 & 4 \\
\hline 9 & - & - & - & 1 & 2 & - & - & - \\
\hline 10 & - & - & $\mathbf{1}$ & - & 1 & - & - & 1 \\
\hline 11 & - & - & - & 1 & - & - & - & - \\
\hline 12 & - & - & - & - & - & - & 2 & 1 \\
\hline 14 & - & - & - & - & - & - & 2 & 1 \\
\hline 16 & - & - & - & - & - & 1 & - & - \\
\hline 17 & - & - & - & - & - & - & - & 1 \\
\hline 20 & - & - & - & - & - & 1 & - & - \\
\hline 21 & - & - & - & - & - & 1 & - & - \\
\hline 53 & - & - & - & - & 1 & - & - & - \\
\hline $\begin{array}{l}\text { Total no. of } \\
\text { aggregates }\end{array}$ & 117 & 104 & 104 & 96 & 145 & 150 & 155 & 174 \\
\hline $\begin{array}{l}\text { Total no. of } \\
\text { cells }\end{array}$ & 219 & 219 & 187 & 181 & 339 & 348 & 360 & 397 \\
\hline$\frac{\text { Aggregates }}{\text { Total cells }}$ & 0.53 & 0.47 & 0.56 & 0.53 & 0.43 & 0.43 & 0.43 & $0 \cdot 44$ \\
\hline
\end{tabular}

The staining of dead cells in direct count preparations may be expected to introduce a serious error. That many hyphal pieces observed under the microscope seem empty of protoplasmic contents and are purplish in colour instead of the intense blue shown by known actively growing mycelium was pointed out by Jones \& Mollison (1948). To a lesser degree bacterial cells of varying intensity of blue can be seen, but to attempt to separate viable from non-viable particles by depth of colour would be too arbitrary a procedure. It is interesting to note that Taylor (1936), in experiments with soil cultures of bacteria (all of which were able to grow on a soil extract agar), found a plate count on this same medium to be $36-61 \%$ of a direct count estimated by the ratio technique of Thornton \& Gray (1934), which gives counts of a magnitude similar to that given by the method used in the present work. As shown in Table 6 a difference of $36-61 \%$ can be accounted for if clumps of several cells develop into single colonies on plates, and thus cannot necessarily be attributed to the staining of non-viable cells. On the other hand, the number of non- 
viable but stainable cells may accumulate with time and may therefore be greater in a field soil than in an artificial soil population incubated for the relatively short periods used by Taylor. At present, the separation of viable from non-viable organisms in direct counting remains impracticable.

The difficulty of distinguishing bacteria from actinomycete spores is well known. These spores abound in soils, and there is strong evidence that in some soils actinomycetes may be present largely in this form (Skinner, 1951). Allowing that some actinomycetes may not develop on plates, it seems possible that almost the whole actinomycete count of $10-15 \mathrm{million} / \mathrm{g}$. soil is included in the direct bacterial count. However, unless there are vast numbers of dead actinomycete spores present, this source of error cannot be a large one as the actinomycete plate count is small compared with the direct bacterial count.

Competition between colonies on plates and the antagonistic suppression of one species by another are factors which may cause a lower plate count, but no evidence can be presented to show that they were operating in the present investigation.

It has been shown that the growth of single colonies from bacterial aggregates would account for a plate count only half the corresponding direct count. However, this alone is inadequate to explain the enormous discrepancy between numbers given by the two methods. The most probable further causes of this discrepancy would seem to be the counting of non-viable particles in soil films (tending to increase the direct count) and selectivity of the plating medium, a well-known limitation of all plating techniques tending to reduce the plate count.

The ratio fungal plate count : direct count is only $1: 2-6$; selectivity of the plating medium and the direct counting of non-viable fragments could explain this small difference satisfactorily. In view of Skinner's (1951) results, it seems unlikely that actinomycete fragments contribute appreciably to the fungal direct count. It is important to remember that different soil conditions may encourage sporulation of fungi rather than mycelial growth. For this reason a plate count may give a false picture of mycelial development while a direct count may give a truer analysis.

Many studies on the effect of external factors on the fluctuating numbers of micro-organisms have been made, and although the results have often been contradictory, most workers consider that variations in soil moisture content must have some effect on the micro-population, although Taylor (1936) showed that fluctuations of bacterial numbers took place while soil moisture content and temperature were kept constant. It is evident that neither direct nor plate counting records accurately changes in the total numbers of soil microorganisms. In direct counts such fluctuations may be masked by an accumulation of non-viable but stainable cells. The selectivity of plating media and the fact that here plate counts of bacteria were positively and direct counts negatively correlated with temperature suggest that the plate count is an estimate of one element of the soil population, which reacts to external factors differently from the total population. With these considerations in mind it is 
easier to understand the absence of correlations between plate and direct counts.

Plate counting is a well-established method, perhaps of greatest value for qualitative investigation. We consider that the new direct-counting technique, though it undoubtedly gives an overestimate of the viable population, has proved reliable for quantitative investigations. It is rapid, and as both bacteria and fungi can be examined in the same soil film, it saves labour and equipment necessary for plating experiments.

Two of us (F.A.S. and J.E.M.) held grants from the Agricultural Research Council when this work was undertaken. We wish to record our thanks to Dr H. G. Thornton, F.R.S., for his helpful advice, to J. H. A. Dunwoody for assistance with the statistical work, and to Miss Mabel Dunkley for preparation of the typescript.

\section{REFERENCES}

Brierley, W. B., Jewson, S. T. \& Brierley, M. (1927). A quantitative study of soil fungi. Int. Congr. Soil Sci. 3, 48.

Erikson, D. (1947). Differentiation of the vegetative and sporogenous phases of the Actinomycetes. 2. Factors affecting the development of the aerial mycelium. J. gen. Microbiol. $1,45$.

Fred, E. B. \& WAKsman, S. A. (1928). Laboratory Manual of General Microbiology. New York: McGraw-Hill.

Jones, P. C. T. \& Mollison, J. E. (1948). A technique for the quantitative estimation of soil micro-organisms. J. gen. Microbiol. $2,54$.

Singr, B. N. (1949). The effect of artificial fertilizers and dung on the numbers of amoebae in Rothamsted soils. J. gen. Microbiol. 3, 204.

Singh, J. (1937). Soil fungi and actinomycetes in relation to manurial treatment, season and crop. Ann. appl. Biol. 24, 154.

SkinNer, F. A. (1951). A method for distinguishing between viable spores and mycelial fragments of actinomycetes in soils. J. gen. Microbiol. 5, 159.

TAYLOR, C. B. (1936). Short period fluctuations in the numbers of bacterial cells in soil. Proc. Roy. Soc. B, 119, 269.

Thornton, H. G. \& Gray, P. H. H. (1934). The numbers of bacterial cells in field soils, as estimated by the ratio method. Proc. Roy. Soc. B, 115, 522.

Waksman, S. A. (1927). Principles of Soil Microbiology. London: Baillière, Tindall and Cox.

(Received 30 August 1951) 